\title{
Ascus Cytology of Podospora anserina
}

\author{
By A. BECKETT* AND IRENE M. WILSON \\ University College of Wales, Aberystwyth
}

(Accepted for publication I4 March 1968 )

\begin{abstract}
SUMMARY
The ascus cytology of Podospora anserina (Ces.) Rehm, a secondarily homothallic Pyrenomycete fungus, has been followed under the light microscope from the crozier, through karyogamy and the three nuclear divisions in the ascus (the first two constituting a meiosis and the third a mitosis) to the first spore mitosis and spore maturation. The spindles remain widely separated at division II, during which segregation for mating type is said to occur. After division III, in which the spindles are transverse, the ascus contains four pairs of sister nuclei. The realignment of the nuclei so that two non-sister nuclei are included in each of the four spores is brought about by the movements of the centrosomes or, more likely, of their outer portions. Spore delimitation, which starts from these organelles, appears as a thin cleavage line separating the spore plasm from the epiplasm of the ascus. A mitosis in the spore initial followed by degeneration of one of the four daughter-nuclei in the primary appendage leads to an imbalance in the mating-type factors in the spore. The wall of the mature spore is separable into three layers, the middle one of which is pigmented. The mucilaginous secondary appendage formed at each end of the spore is already present before the primary appendage is cut off.
\end{abstract}

\section{INTRODUCTION}

Podospora anserina (Ces.) Rehm is a Pyrenomycete fungus which has been the subject of many genetic studies. Its life-cycle was described by Ames (1932, 1934) and Dodge (1936) and some observations on its cytology were published by Moreau \& Moreau (1951), Franke (1957, 1962) and Heslot (1958). An attempt is made here to give a more complete account of the cytology.

\section{METHODS}

Cultures of Podospora anserina were grown in Petri dishes on a medium of sheep dung agar, at room temperature in continuous light. Small pieces of sterile filter paper were mixed with the medium to enhance perithecial production.

Blocks of agar, approximately $3 \mathrm{~mm}^{3}$ and containing numerous young perithecia, were fixed for $15 \mathrm{~min}$. under vacuum in either $\mathrm{I}: 3(\mathrm{v} / \mathrm{v})$ acetic acid: ethanol solution, or $a \mathrm{I}: 3(\mathrm{v} / \mathrm{v})$ propionic acid: ethanol solution, after which they were left in fixative at room temperature for periods of $24 \mathrm{hr}$ to 6 weeks. The blocks were then washed for 2-24 hr under running water before treatment with a saturated solution of cytase (S/40I G.T. Gurr Ltd) for Io hr. They were again washed in running water for $\mathrm{I} \mathrm{hr}$ and then placed in a $400 \mu \mathrm{g}$. $/ \mathrm{ml}$. solution of ribonuclease and incubated for $12-24 \mathrm{hr}$ at

* Present address: Department of Botany, University of Bristol, Bristol, 8. 
$35^{\circ}$. The blocks were then washed for a further hour, mordanted at room temperature in a $4 \%(\mathrm{w} / \mathrm{v})$ iron alum solution and given a final wash for $30 \mathrm{~min}$. prior to staining.

Perithecia were removed from the blocks and the asci dissected out into a drop of propiono-carmine on a glass slide. After adding more stain, the slide was heated to $60^{\circ}$ and the asci squashed flat under a coverslip, excess stain being blotted up. Slides were then ringed with D.P.X. Mountant and allowed to cool down to room temperature.

Satisfactory preparations were obtained by this method, showing all stages from synapsis in young asci to division IV in the ascospores. However, in studying the croziers, the Feulgen-propiono-carmine technique of McIntosh (1954) gave better results in that hydrolysis for $8 \mathrm{~min}$. in $\mathrm{N}-\mathrm{HCl}$ caused the young asci to separate clearly on squashing and enabled the relative positions of the cross-walls and nuclei to be easily seen. Observations of maturing spores were made difficult by their increasing pigmentation.

All preparations except Pl. 2, fig. 20 were examined and photographed on a Zeiss Standard Universal Microscope fitted with a Zeiss Icon $35 \mathrm{~mm}$ camera. Photographs were taken on Kodak Panatomic-X film with the aid of phase contrast and a medium green filter, and developed in Kodak Microdol-X developer. All prints were made on Ilfobrom paper. Plate 2, fig. 20 was photographed on a Baker phase-contrast microscope fitted with a Trilux condenser and a Watson fixed-plate camera, using a Kodak B. 4 half-tone plate.

\section{RESULTS}

\section{Croziers, karyogamy and division I}

A typical crozier with a binucleate, penultimate cell and unicucleate terminal and stalk cell is shown in Pl. I, fig. I. The two nuclei in the penultimate cell fuse soon after the penultimate cell begins to enlarge to form the ascus (PI. I, fig. 2-4). Meanwhile, the stalk and terminal cell of the crozier unite (Pl. I, fig. 3, 4) and the binucleate cell so formed is capable of growing out to form another crozier. This conforms with the normal development in Eu-ascomycetes and does not support the early observations from sections by Faull (1905).

The diploid nucleus resulting from karyogamy contains a single very large nucleolus. Contraction of the chromosomes and synapsis occur while the ascus is still only $15-20 \mu$ in length (Pl. 1 , fig. 2 (right), 4). When the ascus reaches 40-50 $\mu$ in length, the chromosomes are somewhat longer and are fully paired (P1. I, fig. 5, 6). When the ascus is 100-1 $20 \mu$ long, the chromosomes are fully extended at full pachytene (Pl. I, fig. 7-9). At this stage chromomeres are readily seen on the chromosomes and the nucleolus has a diameter of about $7 \mu$. Synapsis, while the chromosomes are in a contracted condition, followed by pachytene elongation have been described at meiosis in other Pyrenomycetes including Neurospora crassa (Singleton, 1953) and Sordaria fimicola (Carr \& Olive, 1958).

At early diplotene (Pl. I, fig. IO, I I) and diakinesis (Pl. 2, fig. I2) the chiasmata are apparent. At diakinesis seven contracted bivalents can be counted in well spread out preparations (Pl. 2, fig. I2). By metaphase I (Pl. 2, fig. I3, I4) the seven highly condensed bivalents can be seen near the centre, but at slightly different levels, on the well developed intranuclear spindle. There are crescent-shaped centrosomes, at each pole and astral rays can be seen in P1. 2, fig. I4, (top). The spindle is always arranged 
parallel to the long axis of the ascus. It remains clearly visible throughout anaphase (P1. 2, fig. 15-I8). The nucleolus, pushed out to one side of the spindle at metaphase, diminishes in size and gradually disappears during anaphase. New nucleoli are produced in each of the two daughter nuclei (P1. 2, fig. 19).

\section{Division II}

In the two daughter-nuclei, now well separated from each other, the chromosomes show the relic anaphase arrangement (P1.2, fig. 19), and remain considerably contracted throughout division II, although the reformed nucleoli increase in size. In Pl. 2, fig. 20, the upper nucleus is at metaphase and the lower at prometaphase, illustrating a slight basipetal succession in the nuclear divisions in the ascus. The spindles at division II have well marked rod-shaped centrosomes at their poles and are orientated either vertically or obliquely in the ascus, but they are so far apart that it is unlikely that they slip past each other at anaphase (Pl. 2, fig. 20). This division completes meiosis.

\section{Interphase II and division III}

Following division II there is a well marked interphase (Pl. 2, fig. 2I) during which the nuclei lie in two widely separated pairs, each pair presumably consisting of sister nuclei. Almost invariably, the centrosomes of the upper pair face the base of the ascus while those of the lower pair face the apex, as noted by Heslot (1958). The chromosomes become greatly elongated during this interphase.

In all the preparations seen of division III, spindle orientation was transverse to the long axis of the ascus (P1. 2, fig. 22, 23) and not vertical as suggested by Franke (1957). Spindle elongation at late anaphase III brings the centrosomes and associated chromosome groups close to the wall of the ascus (P1. 2, fig. 22, 23, lower right). This division is a normal mitosis.

\section{Interphase III to ascospore delimitation}

Interphase III nuclei are characterized by a distinct nuclear 'beak' apparently formed by the drawing out of the nuclear membrane at its point of attachment to the centrosome (Pl. 3, fig. 24-27). From many observations of asci at this stage it is clear that there is a regular arrangement of the nuclei in pairs resulting from division III (Pl. 3, fig. 27). Starting from the apex of the ascus, the centrosomes (or part of them) then move in a downward direction, away from their related nuclei, and come to lie close to the ascus wall (Pl. 3, fig. 28). In the next stage, which is less clear owing to an increase in granularity of the ascus cytoplasm, the centrosome bodies can be seen as densely staining plates, in pairs, close to the wall of the ascus (P1. 3, fig. 29). On close examination a light-coloured cleavage line can be seen, starting from each of the paired centrosome bodies, extending back around two nuclei and enclosing them within long, cigar-shaped spore initials. It is apparently by the movement of the centrosome bodies away from their own nuclei and their association in pairs below non-sister nuclei that two such nuclei become included within each of the four binucleate spore initials (P1. 3, fig. 30). Occasionally, uninucleate spores are cut out (Pl. 3, fig. 3I) and are of the normal form. Asci with the uninucleate spores may contain three binucleate and two uninucleate spores or one trinucleate, one uninucleate and two binucleate spores. 


\section{Division IV, maturation of the spore and development of spore appendages}

A fourth division within the spore initial, previously described by Moreau \& Moreau (195I) and Heslot (1958) but denied by Franke (1957), is confirmed (Pl. 3, fig. 32). The division occurs in the spore head in such a way that four nuclei are produced, three remain in the head and one migrates into the narrower tail, and the latter now becomes cut off by a wall. This nucleus aborts and the cytoplasmic contents disappear to form a vacuolated, hyaline primary appendage. The wider, distal part of the spore initial containing three nuclei enlarges to form the spore itself. It becomes darkly coloured during development. When the spore is crushed the wall separates into three layers, the middle one of which is pigmented. There is a germ pore at the apical end of the spore. Two mucilaginous, secondary appendages, one almost apical at the side of the germ pore and one below the primary appendage, can be discerned at a very early stage of spore development, before the primary appendage has been cut off, but observations made with the optical microscope did not reveal how these appendages arise.

\section{DISCUSSION}

The haploid chromosome number of seven agrees with a metaphase I count by Franke (1962) and is in conformity with the seven linkage groups recorded by Kuenen (I962) from a genetic analysis of gene mutants.

The spindle orientation is more or less vertical at I and II (with the products of division I widely separated from each other) and transverse in III. This differs from the account of Franke (1957), but agrees with that of Heslot (1958). It is through the movements of the centrosome bodies that the four pairs of sister-nuclei resulting from division III are realigned to form four pairs of non-sister nuclei which are then incorporated in the four binucleate spore initials. This process is important since Podospora anserina is secondarily homothallic and the two nuclei in each spore are normally of different mating type, segregation for this factor having occurred, according to the genetic evidence, in division II (Rizet \& Engelmann, 1949). These cytological observations agree with the theoretical scheme put forward by Esser \& Kuenen (I965) which shows that on the spindle orientation described here, and post-reduction, each spore will contain a $(+)$ and a $(-)$ nucleus.

The mitosis in the binucleate spore and the degeneration of one of the four resulting nuclei in the primary appendage leads to the formation of a spore containing either one $(+)$ and two $(-)$ nuclei or one $(-)$ and two $(+)$ nuclei. No consideration appears to have been given by geneticists to possible consequences of this imbalance.

The term 'centrosome' or 'centriole' has been used rather loosely for the same body in the literature on the cytology of the Ascomycetes. In Podospora anserina the centrosome has been depicted as a disc in division I, as a rod in divisions II and III and as a plate at the nuclear 'beak' and spore delimitation stages. Similar appearances have been described in other Pyrenomycetes such as Neurospora tetrasperma (Colson, 1934), N. crassa (Singleton, 1953), Podospora spp. and Sordaria macrospora (Heslot, I958) and S. fimicola (Carr \& Olive, I958; Doguet, 1960), and it has been noted that the centrosome appears to enlarge at the later divisions. Singleton (I953) suggested that this growth might be in some way related to the functioning of the centrosome in spore delimitation and perhaps did not involve that part of the centrosome which has 
genetic continuity in relation to the spindle. Recent work by Schrantz (1967) on the fine structure of the Discomycete Pustularia cupularis has shown that the so-called centrosome is bipartite; the inner disc is associated with the spindle fibres and the outer disc carries the astral rays, which do not themselves fuse to form the cell wall, but do, in some way, appear to control the delimitation of the spore by the endoplasmic reticulum, outside the rays themselves. The centrosome in yeast also consists of two discs (Robinow \& Marak, 1966).

In the light of these observations it seems reasonable to suggest that in Podospora anserina also, it is only the outer part of the centrosome which moves away from the nucleus with which it was associated and functions in spore delimitation while the inner part remains closely associated with the nuclear membrane, ready to function at the next mitosis. This hypothesis needs to be tested by electron-microscope studies.

Heslot (I958) suggested three functions for the centrosome-the control of nuclear division, the delimitation of the ascospores and the orientation of the spores. It now appears that the first function belongs to the inner disc of the centrosome and the two latter functions to the outer part. To these an additional function, the association of nuclei of different mating type prior to spore formation in the secondarily homothallic $P$. anserina, can be added. Doguet (1960) has argued that the spindle controlling body probably divides during interphase and that during the subsequent nuclear division the spindle is formed between the two separating halves. The close association of the centromeres of the chromosomes and this body throughout each interphase may be significant.

Although the techniques employed in this investigation were not the most suitable for showing the astral rays and their possible role in spore delimitation, it was clearly demonstrated that cleavage of the spore plasm is initiated from the centrosome bodies and gradually extends up to include two non-sister nuclei.

While this work was in progress, A. Beckett was supported by an S.R.C. Research Studentship at Aberystwyth and an S.R.C. Post-doctoral Fellowship at Bristol. Professor P. F. Wareing and Professor L. E. Hawker are thanked for the facilities provided in their departments.

\section{REFERENCES}

Ames, L. M. (1932). An hermaphroditic self-sterile but cross-fertile condition in Pleurage anserina. Bull. Torrey bot. Club. 59, $34 \mathrm{I}$.

AMES, L. M. (1934). Hermaphroditism involving self-sterility and cross-fertility in the Ascomycete Pleurage anserina. Mycologia 26, 392.

Carr, A. J. H. \& Olive, L. S. (1958). Genetics of Sordaria fimicola. II. Cytology. Am. J. Bot. 45, I42.

Colson, B. (1934). The cytology and morphology of Neurospora tetrasperma Dodge. Ann. Bot. 48, $2 I I$.

Dodge, B. O. (1936). Spermatia and nuclear migrations in Pleurage anserina. Mycologia $28,284$.

Doguet, G. (1960). Contribution à l'étude du noyau du Sordaria fimicola. Rev. Cytol. Biol. veg. 22, IO9.

EsSER, K. \& Kuenen, R. (1965). Genetic der Pilze. Berlin-Heidelberg-New York: Springer-Verlag.

FAULL, J. H. (1905). Development of the ascus and spore formation in Ascomycetes. Proc. Boston Soc. nat. Hist. 32, 77.

Franke, G. (1957). Die Cytologie der Ascusentwicklung von Podospora anserina. Z. indukt. Abstamm.u. VererbLehre 88, 159. 
Franke, G. (1962). Versuche zur Genomverdoppelung des Ascomyceten Podospora anserina (Ces.) Rehm. Z. VererbLehre 93, 109.

Hestot, H. (1958). Contribution à l'étude cytogénétique et génétique des Sordariacées. Rev. Cytol. Biol. veg. 19, I.

Kunnen, R. (1962). Crossover- und Chromatiden-Interferenz bei Podospora anserina (Ces.) Rehm. Z. VererbLehre 93, 66 .

McINTosh, D. L. (1954). A Feulgen-carmine technique for staining fungus chromosomes. Stain Technol. 29, 29.

Moreau, F. \& Moreau, Mme. (195I). Observations cytologiques sur les Ascomycètes du genre Pleurage Fr. Revue Mycol., Paris 16, 198.

Rizet, G. \& Engelmann, C. (1949). Contribution à l'étude génétique d'un Ascomycète tetrasporé: Podospora anserina (Ces.) Rehm. Rev. Cytol. Biol. veg. II, 202.

Robinow, C. E. \& MaraK, J. (I966). A fibre apparatus in the nucleus of the yeast cell. J. Cell Biol. 29, I 29.

SChrantZ, J.-P. (1967). Présence d'un aster au cours des mitoses de l'asque et de la formation des ascospores chez l'Ascomycète Pustularia cupularis (L.) Fuck. C. r. hebd. Séanc. Acad. Sci., Paris 264, 1274.

Singleton, J. R. (1953). Chromosome morphology and the chromosome cycle in the ascus of Neurospora crassa. Am. J. Bot. 40, 124.

\section{EXPLANATION OF PLATES}

\section{Plate I}

Fig. I. Crozier on ascogenous hypha, with penultimate, binucleate cell beginning to enlarge. $\times 2240$.

Fig. 2. Ascogenous hyphae and young asci. $\times 1400$.

Fig. 3. Two young asci, uninucleate after karyogamy, and fusion of the apical and stalk cell of the croziers. $\times 1400$.

Fig. 4. Group of ascogenous hyphae, croziers and asci. $\times 1400$.

Fig. 5. Young ascus with fusion nucleus showing chromosomes synapsed. $\times 1400$.

Fig. 6. Young ascus. Paired chromosomes have begun to elongate. $\times 1400$.

Fig. 7. Ascus with chromosomes at early pachytene. Note enlarged nucleolus and chromomeres visible on some of the chromosomes. $\times 1400$.

Fig. 8, 9. Two focal planes of ascus at full pachytene. $\times 1400$.

Fig. IO, II. Two focal planes of ascus at early diplotene. $\times 1400$.

Plate 2

Fig. 12. Early diakinesis. Chiasmata visible. $\times 1400$.

Fig. 13. Metaphase I. Contracted bivalents on vertical spindle. Crescent-shaped centrosomes at poles. Nucleolus pushed to one side. $\times 2500$.

Fig. 14. Metaphase I. Seven bivalents can be counted. Indications of astral rays at upper pole of spindle. $\times$ I400.

Fig. 15, 16, 17. Anaphase I. Three focal planes showing chromosomes grouping at poles of the vertical spindle. $\times 1400$.

Fig. 18. Late anaphase I. Chromosomes at each pole. Spindle fibres seen as broad band. Nucleolus degenerating. $\times$ I 400 .

Fig. 19. Telophase I. The spindle has disappeared. A nucleolus has appeared related to each of the two groups of chromosomes. $\times 1400$.

Fig. 20. Metaphase and prometaphase II. Spindles vertical and oblique. Centrosomes visible as rods. $\times$ I 400 .

Fig. 21. Interphase II-Prophase III. Two pairs of sister-nuclei widely separated in the ascus. $\times 1400$.

Fig. 22, 23. Anaphase III in two focal planes. Spindles horizontal. Rod shaped centrosomes at poles pushed towards ascus wall. $\times 1400$. 

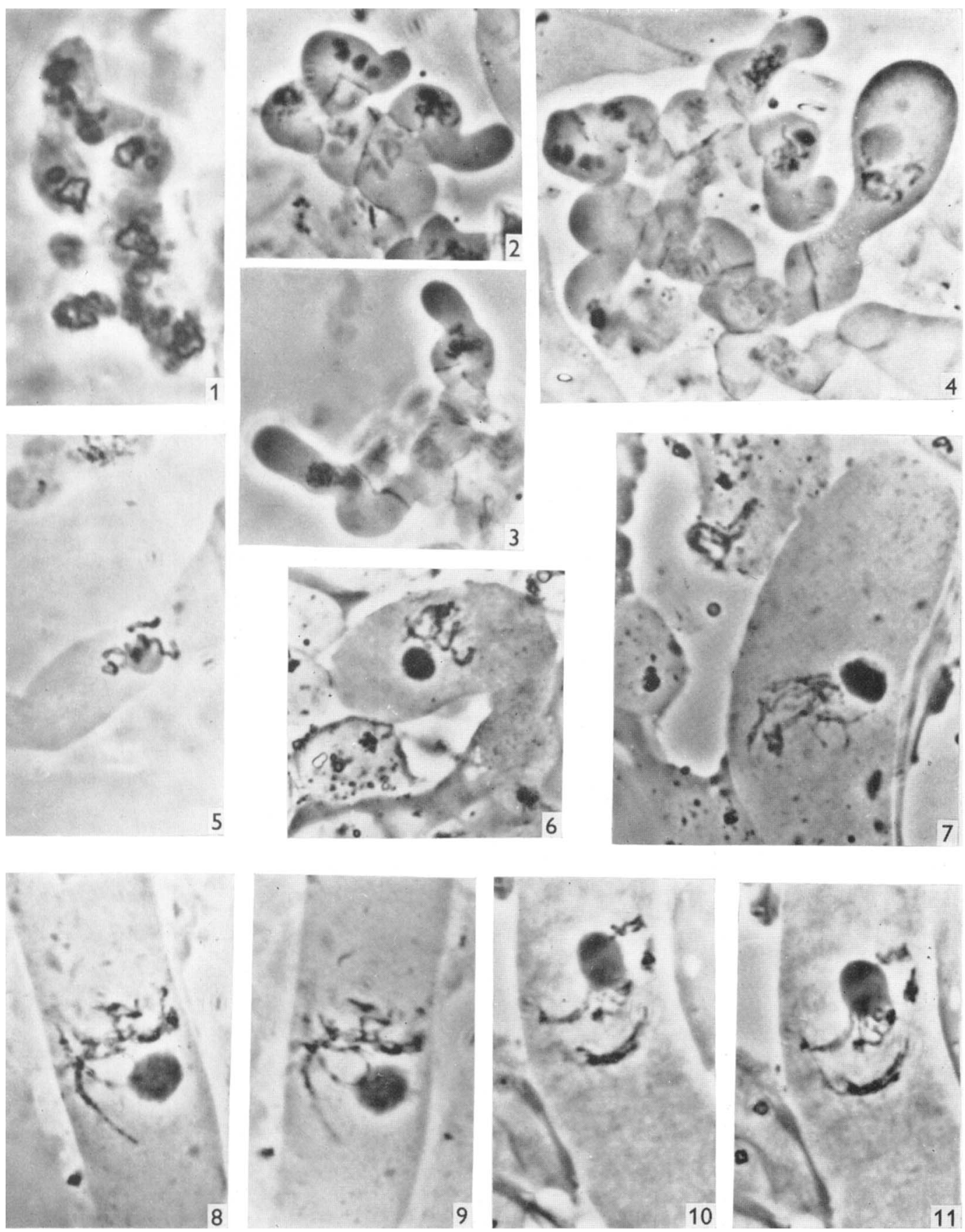
Journal of General Microbiology, Vol. 53, No. I

Plate 2
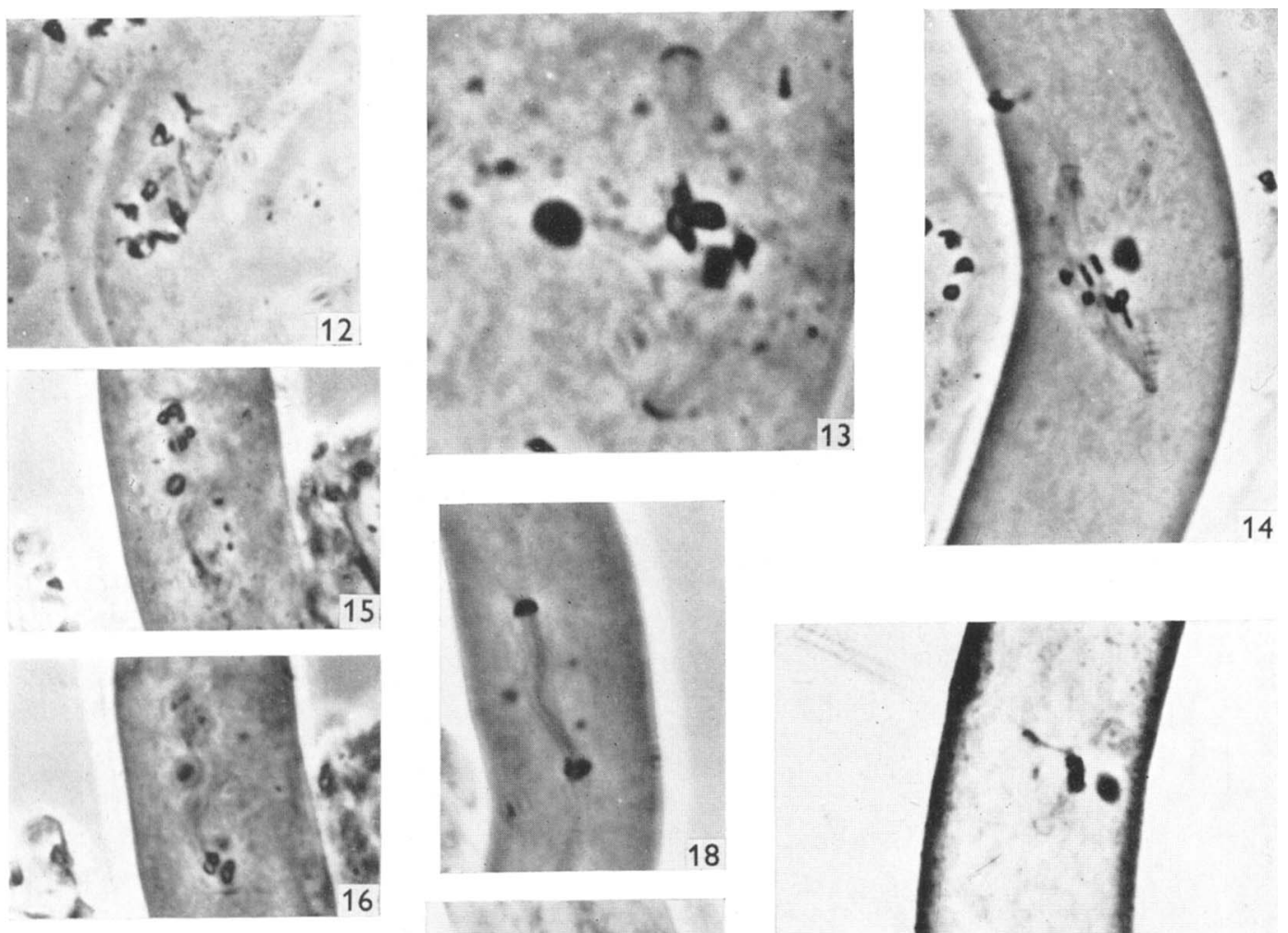

14
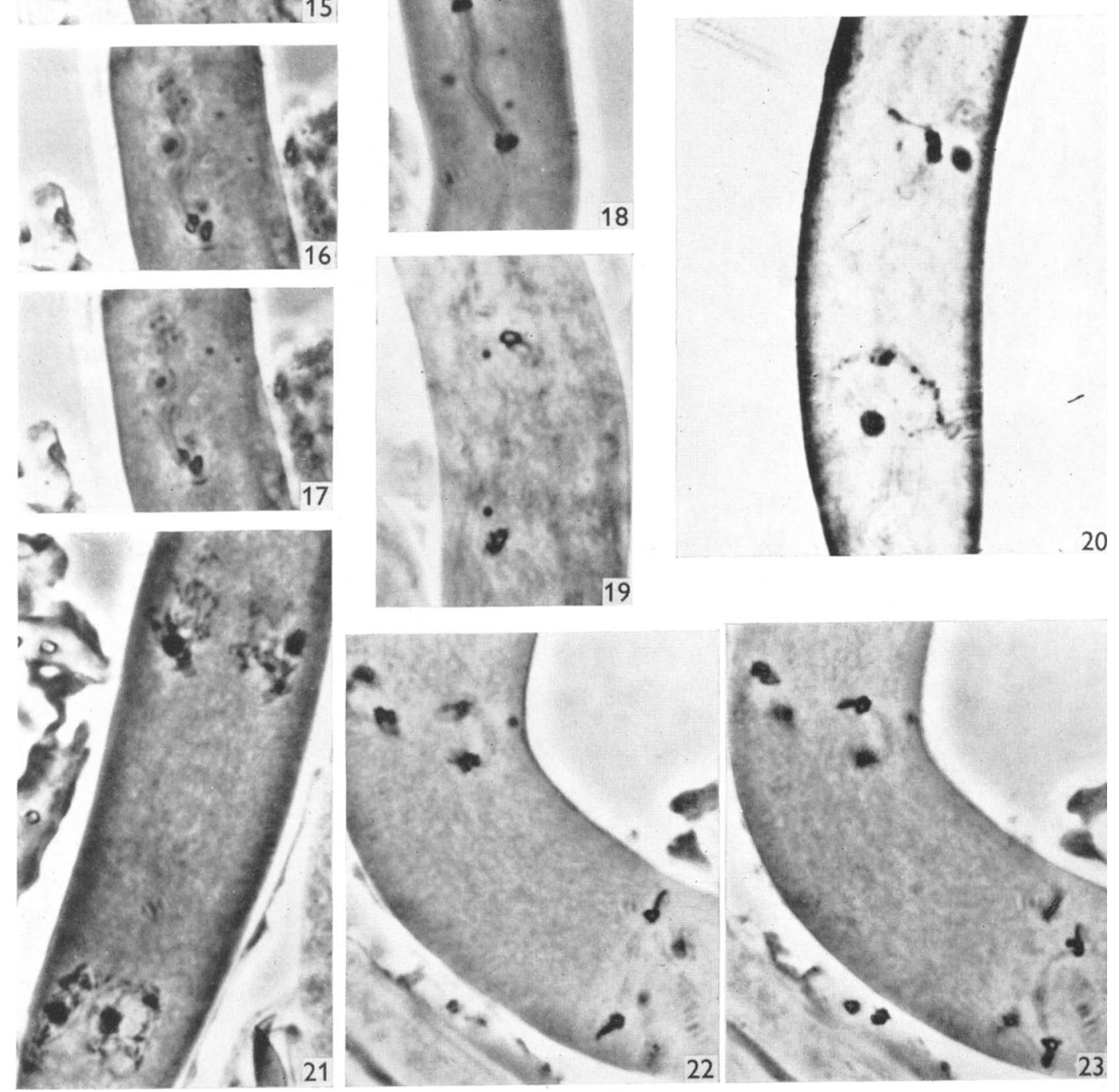

A. BECKETT AND I. M. WILSON

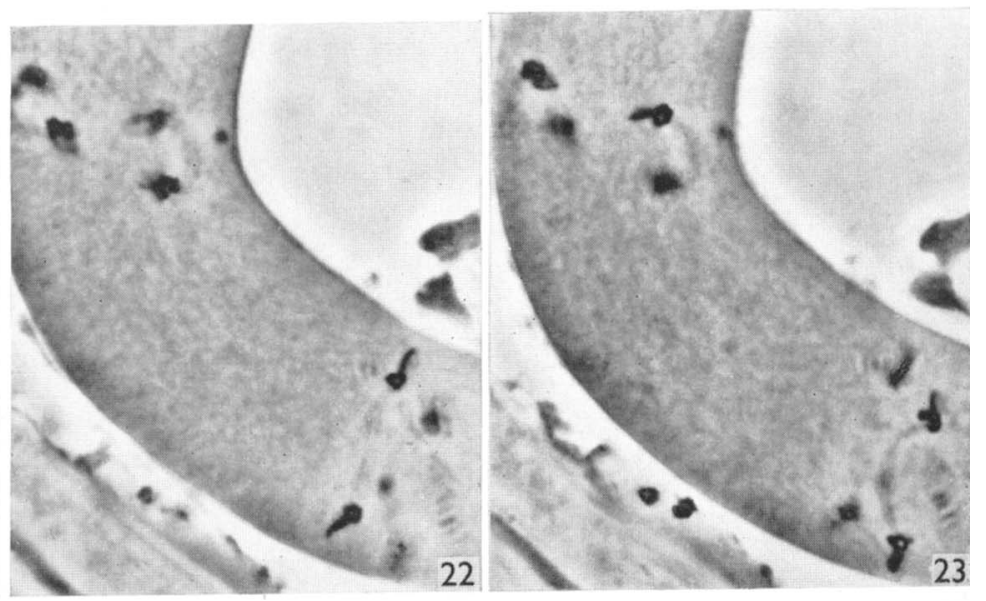


Journal of General Microbiology, Vol. 53, No. I

Plate 3
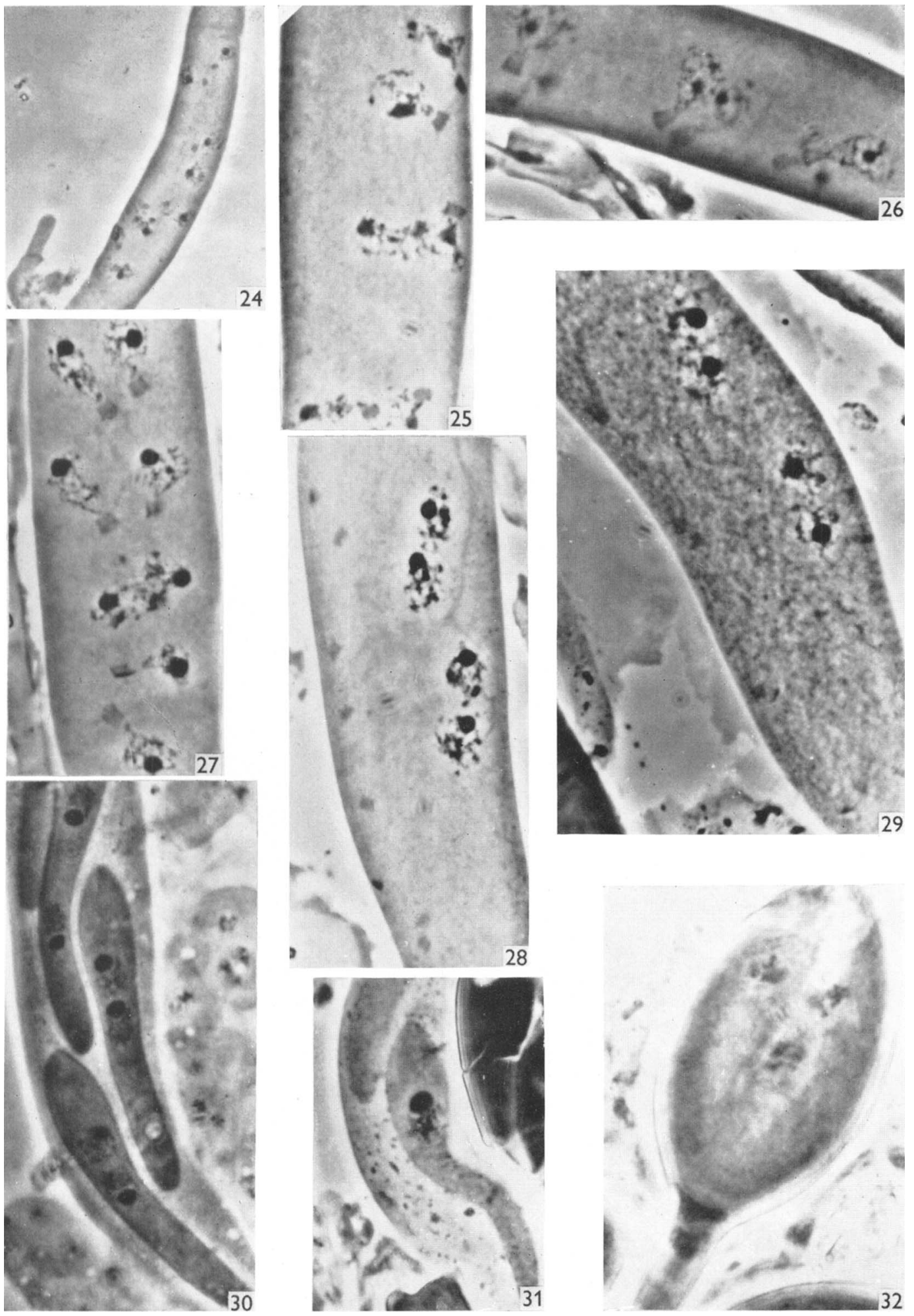

A. BECKETT ANO I. M. WILSON 



\section{Plate 3}

Fig. 24. Ascus showing eight nuclei at interphase III. Centrosomes visible in association with nuclei. $\times 560$.

Fig. 25. Part of ascus with six of the nuclei at interphase III. Prominent nuclear 'beaks' formed by association of nuclear membrane with centrosome. $\times 1400$.

Fig. 26. Part of an unsquashed ascus stained with Feulgen-propionocarmine technique. Centrosomes seen as deeply stained plate-like structures in pairs near to ascus wall. $\times 1400$.

Fig. 27. Pairs of sister nuclei and centrosomes undergoing a basipetal orientation. $\times 1400$.

Fig. 28. Part of ascus, showing later stage in orientation. Centrosomes aligned in pairs adjacent to the ascus wall (left), following a downward migration away from their respective nuclei. $\times$ I 400 .

Fig. 29. Part of ascus at early stage of spore delimitation. Two pairs of nuclei have been cut out by a thin cleavage line in the ascus cytoplasm which is initiated from the centrosomes seen on the left of the ascus. $\times 1400$.

Fig. 30. Three of the four binucleate spore initials shown as discrete bodies after completion of cleavage. Enucleate epiplasm remains in the ascus. Spore initial beginning to show wider spore head and narrower tail portion, the latter towards base of ascus. $\times 1400$.

Fig. 31. Uninucleate spore of normal shape. $\times 1400$.

Fig. 32. Maturing ascospore with three nuclei in the main spore head and one in the tail, now cut off by a septum as the primary appendage. $\times 1400$. 